OPEN ACCESS

Edited by:

Xuming Deng,

Jilin University, China

Reviewed by:

Fuguo Xing

Institute of Food Science and Technology (CAAS), China

Francesca Valerio

National Research Council (CNR), Italy

${ }^{*}$ Correspondence:

Walid A. Lotfy

lotfywalid@yahoo.com

Specialty section:

This article was submitted to

Food Microbiology,

a section of the journal

Frontiers in Microbiology

Received: 04 March 2020

Accepted: 04 June 2020

Published: 15 July 2020

Citation:

Ghanem KM, Lotfy WA

El-Shaer MM and Elassar SA (2020) The Inhibitory Effect of Wheat Husks

Addition on Aflatoxins Production by

Aspergillus flavus in Liquid Culture With Various Wheat Compositions as

Carbon Sources.

Front. Microbiol. 11:1448. doi: 10.3389/fmicb.2020.01448

\section{The Inhibitory Effect of Wheat Husks Addition on Aflatoxins Production by Aspergillus flavus in Liquid Culture With Various Wheat Compositions as Carbon Sources}

\author{
Khaled M. Ghanem ${ }^{1}$, Walid A. Lotfy2*, Mohamed M. El-Shaer ${ }^{1}$ and Samy A. Elassar ${ }^{1}$ \\ ${ }^{1}$ Department of Botany and Microbiology, Faculty of Science, Alexandria University, Alexandria, Egypt, ${ }^{2}$ Department \\ of Microbiology, Faculty of Dentistry, Pharos University in Alexandria, Alexandria, Egypt
}

Wheat may be infected by the aflatoxigenic mold Aspergillus flavus during pre- and post-harvest activities. Control strategies reported to manage aflatoxin contamination of wheat are expensive and require extensive testing to verify the absence of toxic secondary metabolites or newly formed compounds. The objective of this study was to develop an in vitro new control strategy based on assessing the influence of wheat husks on aflatoxin production by $A$. flavus in liquid culture. The results showed that aflatoxin production is significantly influenced by the existence of husks in the wheat forms used as carbon substrates according to the following order: full wheat grains $<$ halfcrushed wheat grains < wheat flour $82 \%<$ wheat flour $72 \%$. By applying a fractional factorial design and a response surface methodology, maximum aflatoxin production (2.567 $\mathrm{ng} / \mathrm{mg})$ was predicted when wheat flour $72 \%(39 \mathrm{~g} / \mathrm{l})$ as a carbon source, yeast extract (5 g/l), and a $75-\mathrm{ml}$ medium volume/250 $\mathrm{ml}$ flask were utilized. At this optimized condition, after addition of wheat husk extract, the growth and synthesis of aflatoxins of $A$. flavus were repressed by 74.85 and $98.72 \%$, respectively. This finding paves the way to examine the antifungal potential of wheat husk constituents and to compare their efficacy with thyme, cinnamon, sweet basil, and coriander essential oils, which possess antimycotic activities. Accordingly, the wheat husk component $\mathrm{SiO}_{2}$ showed the highest growth inhibition (67.04\%) and reduction of $A$. flavus aflatoxins (82.67\%). These results are comparable to those obtained from various examined antimycotic essential oils.

Keywords: Aspergillus flavus, aflatoxins, wheat, response surface methodology, fractional factorial design

\section{INTRODUCTION}

Wheat and wheat products are the main food for four billion people and constitute a major part of the daily human and animal diet. The Food and Agriculture Organization of the United Nations (FAO) estimates the annual world production of wheat in 2015 at approximately 2540 million tons (Food and Agriculture Organization of the United Nations [FAO], 2016). 
Mycotoxins are poisonous secondary metabolites produced by fungi, which are considered one of the most important risks associated with wheat consumption, leading to an annual loss of $\$ 932$ million in stored grains (Cheli et al., 2017). Aflatoxins $\mathrm{B}_{1}\left(\mathrm{AFB}_{1}\right)$ and $\mathrm{B}_{2}\left(\mathrm{AFB}_{2}\right)$, produced typically by the virulent Aspergillus flavus, are the most serious mycotoxins affecting wheat (Bennett and Klich, 2003; Ayalew, 2010; Cheli et al., 2013). Aflatoxins are favorably produced during post-harvest activities, such as transportation and storage, due to poor hygienic conditions, high temperature, and moisture content and heavy rains (Hell et al., 2000; Van Egmond and Jonker, 2004; Cheli et al., 2017), which may result in yield reduction of wheat products due to deterioration of wheat grains (Siuda et al., 2010). Furthermore, aflatoxins have hepatotoxic, mutagenic, immunosuppressive, teratogenic, and carcinogenic effects on humans and animals (Bennett and Klich, 2003).

Many strategies, including physical, chemical, and biological control, have been investigated to manage aflatoxin contamination of wheat (Fandohan et al., 2005; Ni and Streett, 2005; Yin et al., 2008). However, chemical or physical treatment adds to the cost of wheat already damaged from fungal growth. Moreover, extensive testing is required to ascertain that a new compound with a different mode of action has not been formed. Whereas, biological control may pose a potential contamination of wheat with toxic secondary metabolites (Dorner, 2004). On the other hand, wheat husks contain silicon (Terzioğlu and Yucel, 2012), which is reported to control fungal plant pathogens (Sakr, 2016). Therefore, the aim of the present work is to develop an in vitro new preventive management of aflatoxin production by $A$. flavus based on the addition of wheat husks to liquid culture. The latter condition was chosen to provide accelerated fungal growth and to support a manageable comprehensive study of various factors affecting the production of aflatoxins. A fractional factorial design and a response surface methodology were adopted to achieve an optimized maximum production of aflatoxins by A. flavus. This optimized condition was used to evaluate the antifungal potential of wheat husks and wheat husk constituents compared to thyme, cinnamon, sweet basil, and coriander essential oils, which possess antimycotic activities (Mokbel and Alharbi, 2015; Chahal et al., 2016; Khorasani et al., 2017; Debonne et al., 2018). This investigation is important for providing the necessary in vitro knowledge to develop an in vivo study for a sustainable and cost-effective control of aflatoxins. To the best of our knowledge, this method has not been reported for aflatoxins control so far.

\section{MATERIALS AND METHODS}

\section{Wheat Samples}

One of the most commonly cultivated and productive wheat cultivar was selected, namely Sods 12 . A total of 16 wheat samples were collected from farms in the Delta region, Egypt. The samples were maintained in plastic bags in a dark, cold $\left(4^{\circ} \mathrm{C}\right)$, and dry place for not more than 1 month until analysis.

\section{Chemicals}

All chemicals used throughout this study were of analytical grade except for methanol that was of HPLC grade. All chemicals were purchased from Himedia Laboratories (Mumbai, India). Kits used for aflatoxin determination were purchased from VICAM (A Water Business, Milford, DE, United States).

\section{Culture Media}

Dehydrated culture media used throughout this work were purchased from Oxoid (England) or Lab M (England). All media were prepared and sterilized according to the manufacturer's instructions.

Sabouraud dextrose (SD) agar: peptone, $10 \mathrm{~g} / \mathrm{l}$; dextrose, $40 \mathrm{~g} / \mathrm{l}$; agar, $15 \mathrm{~g} / \mathrm{l}$. This medium was used to obtain heavy fungal sporulation that was used for seed inoculation.

Czapek yeast extract (CYE) broth: $\mathrm{K}_{2} \mathrm{HPO}_{4}, 1 \mathrm{~g} / \mathrm{l}$; yeast extract, $5 \mathrm{~g} / \mathrm{l}$; sucrose, $30 \mathrm{~g} / \mathrm{l}$; Czapek concentrate (ml/l), 10. This medium was used for aflatoxin production; under some specified experiments, sucrose was replaced by various forms of wheat.

Czapek concentrate: $\mathrm{NaNO}_{3}, \quad 0.3 \mathrm{~g} / \mathrm{l} ; \mathrm{KCl}, 0.05 \mathrm{~g} / \mathrm{l}$; $\mathrm{MgSO}_{4} .7 \mathrm{H}_{2} \mathrm{O}, 0.05 \mathrm{~g} / \mathrm{l} ; \mathrm{FeSO}_{4} .7 \mathrm{H}_{2} \mathrm{O}, 0.001 \mathrm{~g} / \mathrm{l} ; \mathrm{ZnSO}_{4} .7 \mathrm{H}_{2} \mathrm{O}$, $0.001 \mathrm{~g} / \mathrm{l} ; \mathrm{CuSO}_{4} .5 \mathrm{H}_{2} \mathrm{O}, 0.0005 \mathrm{~g} / \mathrm{l}$.

\section{Preparation of Wheat Samples}

Five kilograms of dried wheat spikes were collected; the weight of husks per kilogram of wheat spikes was $34.3 \mathrm{~g}$. Full wheat grains were classified into four categories by means of sieving as follows: full wheat grains; half-crushed wheat grains of particle size $3 \mathrm{~mm}$ using a woven wire mesh sieve; flour $82 \%$, wheat flour of particle size $0.16 \mathrm{~mm}$ using a nylon mesh sieve followed by adding bran residue after sieving; and flour $72 \%$, wheat flour of particle size $0.16 \mathrm{~mm}$ using a nylon mesh sieve without bran fine. Samples with moisture content between 8 and $14 \%$ were maintained in airtight plastic bags in a refrigerator at $4^{\circ} \mathrm{C}$ until analysis as reported in Sisman and Ergin (2011).

\section{Preparation of Seed Inoculum}

The strain used throughout this work was A. flavus ATCC 16883. Suspension of spores was prepared by culturing A. flavus on SD agar for 5 days and then washing the culture with sterile saline solution $(0.9 \% \mathrm{NaCl})$. Spore suspension was mixed for $1 \mathrm{~min}$ before counting the number of spores by a hemocytometer to adjust the count to the desired concentration.

\section{Production of Aflatoxins by A. flavus}

Aspergillus flavus was cultivated in an aliquot of $50 \mathrm{ml} \mathrm{CYE}$ broth medium $/ 250 \mathrm{ml}$ Erlenmeyer flask. The medium contained $30 \mathrm{~g} / \mathrm{l}$ of various wheat forms, one at a time, as a sole carbon source. It was important to avoid the differences in solubility of wheat forms; therefore, the obtained aflatoxin concentrations were standardized based on the residual total concentration of fermentable sugars in each carbon source (Miller, 1959). The incubation periods were adjusted as indicated in the Results section. After incubation at $28^{\circ} \mathrm{C}$ in a shaking incubator at $180 \mathrm{rpm}$ for the specified incubation period, the growth was 


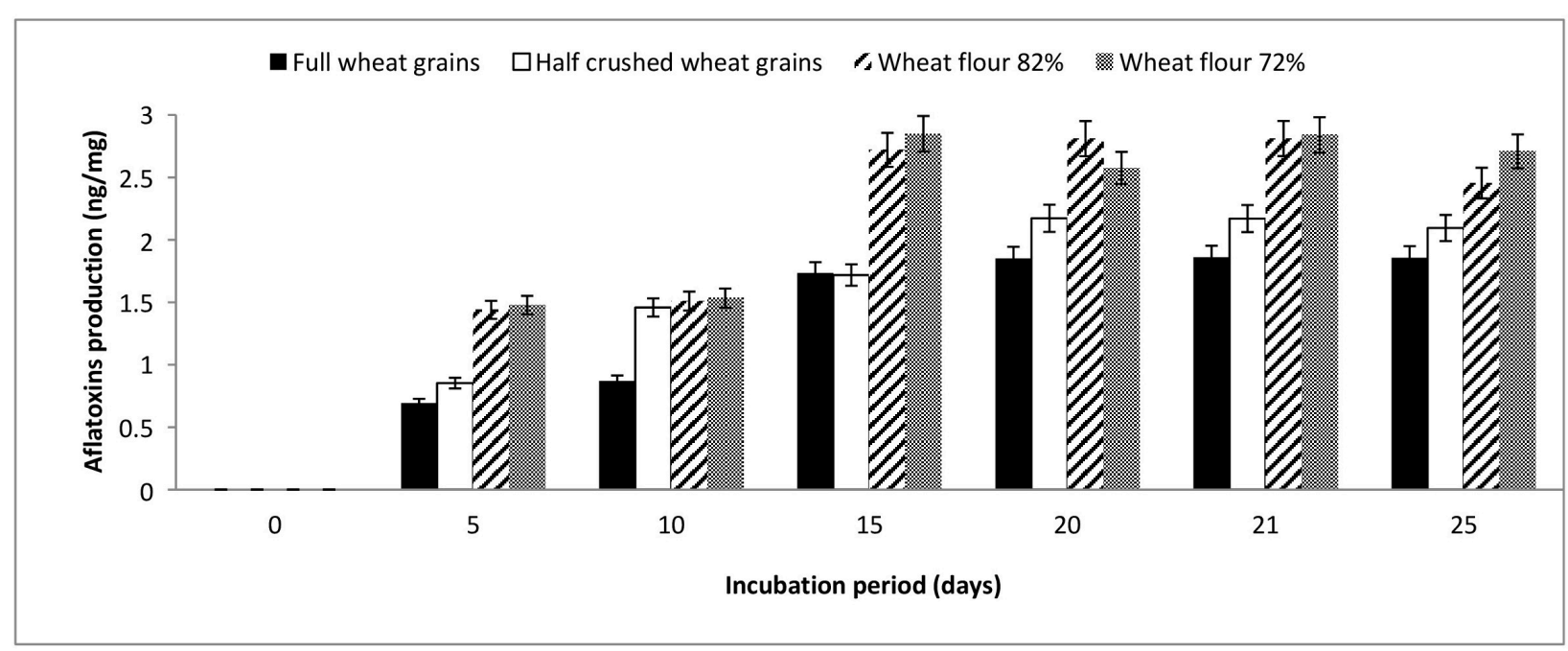

FIGURE 1 | Production of aflatoxins ( $\mathrm{ng} / \mathrm{mg}$ ) by $A$. flavus grown on various forms of wheat grains and wheat flour at different incubation periods.

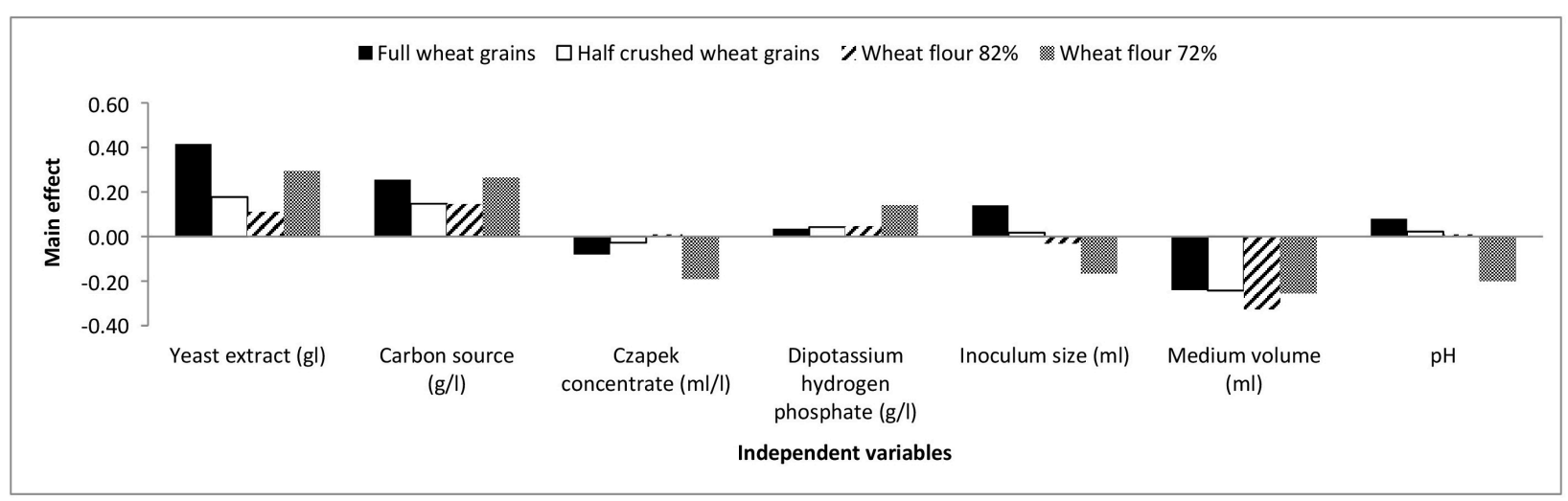

FIGURE 2 | The main effects of independent variables on aflatoxins production ( $\mathrm{ng} / \mathrm{mg}$ ) by $A$. flavus grown on various forms of wheat grains and wheat flour based on the Plackett-Burman experiment.

determined as dry weight, and total aflatoxins were estimated by using a VICAM fluorometer.

\section{Quantitative Determination of Aflatoxins}

Total concentration of aflatoxins (B1, B2, G1, and G2) was measured by using immunoaffinity columns (Aflatest system, VICAM) and fluorometer (VICAM series 4EX) according to the instructions of the manufacturer. Briefly, $25 \mathrm{ml}$ of mycelia-free broth were mixed in blender jar containing $200 \mathrm{ml}$ methanol:water $(80: 20 \mathrm{v} / \mathrm{v})$ for $1 \mathrm{~min}$. The extract was filtered through Whatman filter paper (Cat No. 1001125), and an aliquot of $10 \mathrm{ml}$ of filtrate was transferred into a falcon tube and was diluted with $20 \mathrm{ml}$ distilled water and then filtered through $1.5 \mu \mathrm{m}$ glass microfiber (No. 31955, VICAM). An aliquot of $1 \mathrm{ml}$ of filtered extract was transferred to the immunoaffinity column headspace for filtration at a flow rate of one drop/s by adjusting the speed of the pump (No. 20650 VICAM). Elution was performed by addition of $1 \mathrm{ml}$ methanol, and the eluate was received into a glass cuvette. One milliliter of aflatest developer solution was added to the final eluate in the cuvette. A standard curve was established for quantification of total aflatoxins using VICAM fluorometer. The method of aflatoxins determination was described by the manufacturer and validated before determination (validation parameters: regression $=0.99988$, limit of detection $=0.001 \mathrm{ng} / \mathrm{mg}$, limit of quantification $=0.00303 \mathrm{ng} / \mathrm{mg}$ and relative standard deviation $=0.725 \%)$.

\section{Determination of Fungal Dry Weight}

An aliquot of $3 \mathrm{ml}$ of the broth medium containing mycelia was filtered through a predried (at $60^{\circ} \mathrm{C}$ ) and preweighed filter paper. The filter cake was washed with $20 \mathrm{ml}$ distilled water and dried for $48 \mathrm{~h}$ at $60^{\circ} \mathrm{C}$. The filter cake was allowed to cool in a desiccator and weighed (Lotfy et al., 2007). 

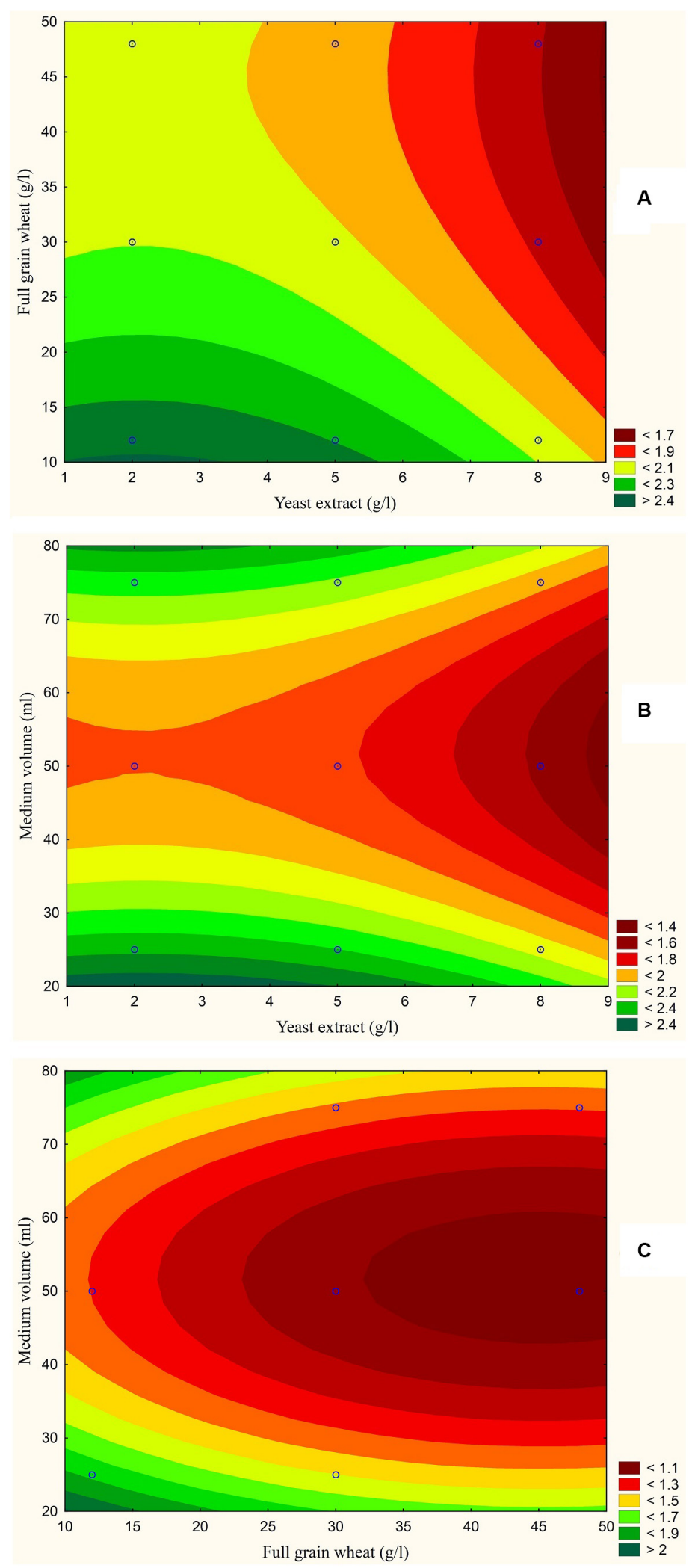

FIGURE 3 | Response contour plot based on the Box-Behnken experimental results. (A) The combined effect of yeast extract (g/l) and full wheat grains (g/l) on aflatoxin production $(\mathrm{ng} / \mathrm{mg})$. (B) The combined effect of yeast extract $(\mathrm{g} / \mathrm{l})$ and medium volume (ml) on aflatoxin production ( $\mathrm{ng} / \mathrm{mg})$. (C) The combined effect of full wheat grains $(\mathrm{g} / \mathrm{l})$ and medium volume $(\mathrm{ml})$ on aflatoxin production $(\mathrm{ng} / \mathrm{mg})$. 

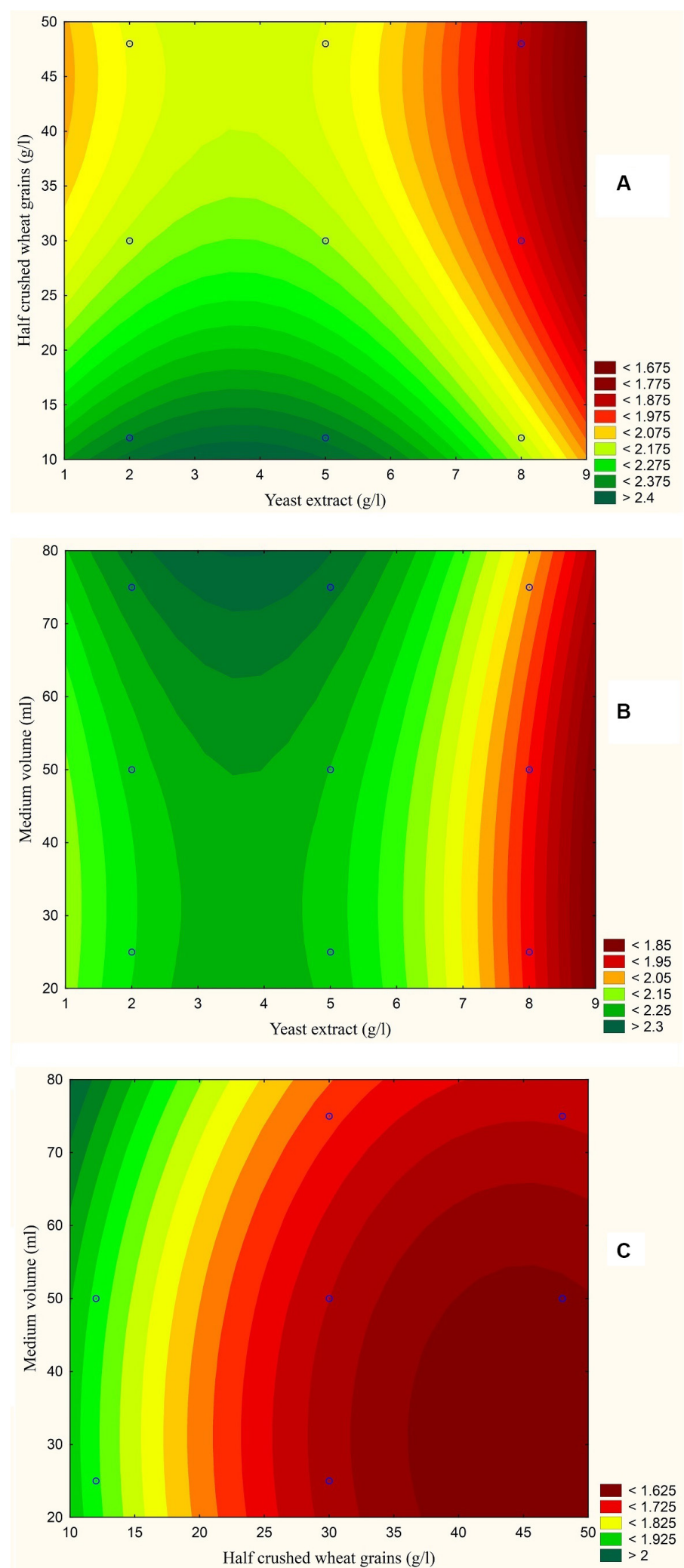

FIGURE 4 | Response contour plot based on the Box-Behnken experimental results. (A) The combined effect of yeast extract (g/l) and half-crushed wheat grains ( $\mathrm{g} / \mathrm{l})$ on aflatoxin production (ng/mg). (B) The combined effect of yeast extract $(\mathrm{g} / \mathrm{l})$ and medium volume (ml) on aflatoxin production (ng/mg). (C) The combined effect of half-crushed wheat grains $(\mathrm{g} / \mathrm{l})$ and medium volume $(\mathrm{g} / \mathrm{l})$ on aflatoxin production $(\mathrm{ng} / \mathrm{mg})$. 

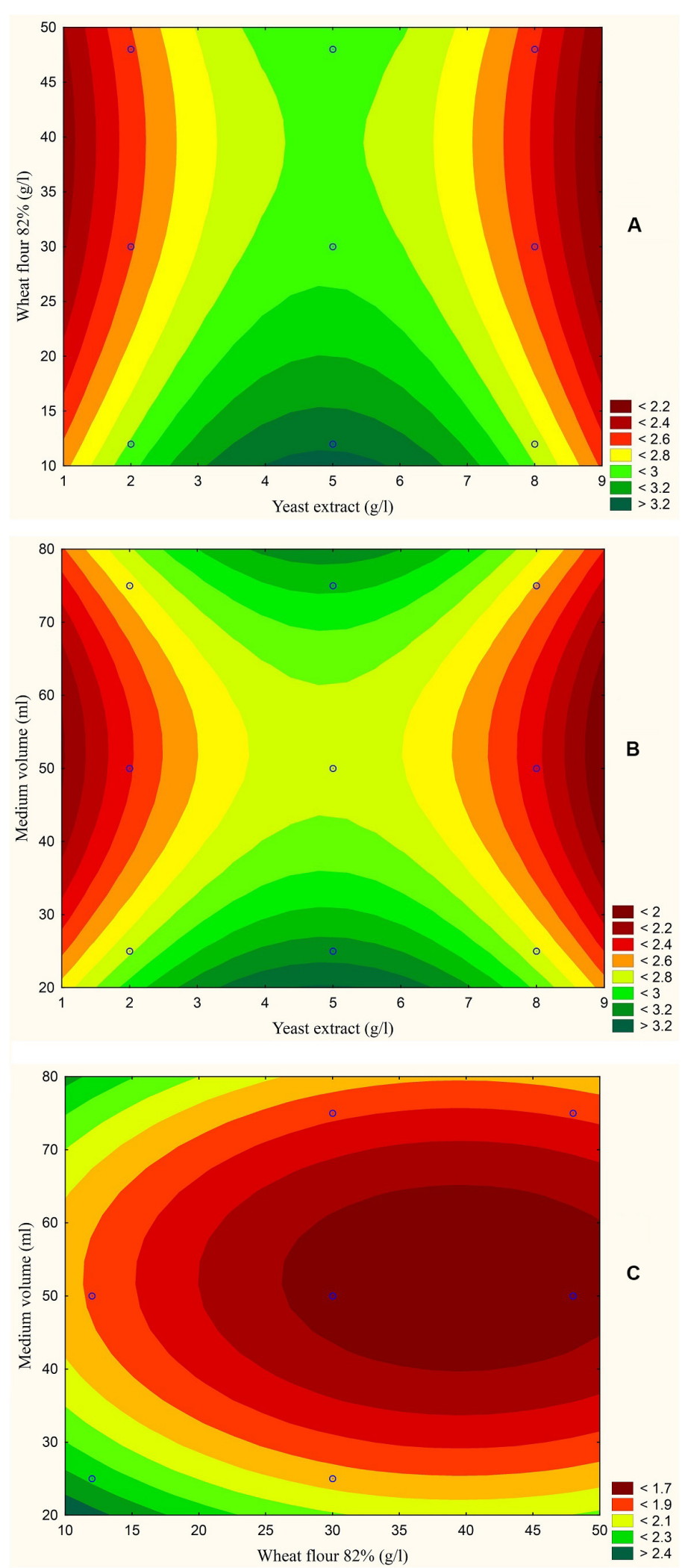

FIGURE 5 | Response contour plot based on the Box-Behnken experimental results. (A) The combined effect of yeast extract (g/l) and wheat flour $82 \%$ (g/l) on aflatoxin production (ng/mg). (B) The combined effect of yeast extract ( $\mathrm{g} / \mathrm{l})$ and medium volume (ml) on aflatoxin production (ng/mg). (C) The combined effect of wheat flour $82 \%(\mathrm{~g} / \mathrm{l})$ and medium volume $(\mathrm{ml})$ on aflatoxin production $(\mathrm{ng} / \mathrm{mg})$. 

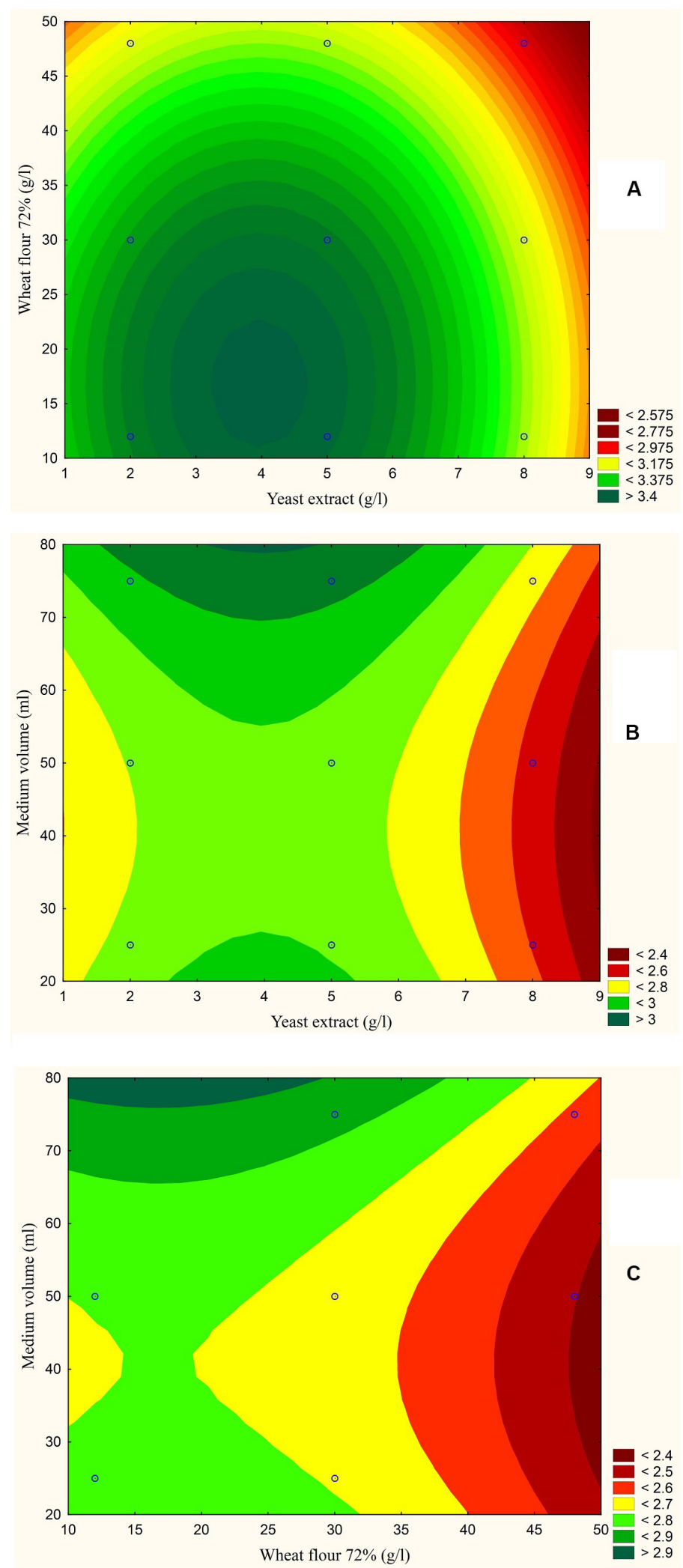

FIGURE 6 | Response contour plot based on the Box-Behnken experimental results. (A) The combined effect of yeast extract (g/l) and wheat flour $72 \%$ (g/l) on aflatoxin production (ng/mg). (B) The combined effect of yeast extract ( $\mathrm{g} / \mathrm{l})$ and medium volume (ml) on aflatoxin production (ng/mg). (C) The combined effect of wheat flour $72 \%(\mathrm{~g} / \mathrm{l})$ and medium volume $(\mathrm{g} / \mathrm{l})$ on aflatoxin production $(\mathrm{ng} / \mathrm{mg})$. 


\section{The Effect of Various Wheat Forms on the Production of Aflatoxins by A. flavus}

Aspergillus flavus was grown on CYE broth containing various forms of wheat grains as carbon sources, one at a time, and aflatoxin production (ng/mg) was monitored at different incubation times $(0,5,10,15,20,21$, and 25 days).

\section{Elucidation of the Factors Affecting Aflatoxin Production by A. flavus}

To maximize the production of aflatoxins by A. flavus, a fraction factorial design, the Plackett-Burman design (Plackett and Burman, 1946; Lotfy et al., 2017), and Box-Behnken design, a response surface methodology, were applied (Box and Behnken, 1960; Lotfy et al., 2018). The purpose of first statistical design was to identify which variable has a significant effect on aflatoxin production by $A$. flavus. In this experiment, seven variables were screened in eight experimental runs, the selected variables included yeast extract, carbon source (various forms of wheat), Czapek concentrate, $\mathrm{K}_{2} \mathrm{HPO}_{4}$, in addition to inoculum size, medium volume/flask, and $\mathrm{pH}$. For each variable, high $(+)$ and low (-) levels were tested, and each trial was performed in triplicate. The main effect and the significance of each variable were determined using Statistica 10 software. The main effect was calculated according to the following equation:

$$
\mathrm{E}_{\mathrm{xi}}=\left(\sum \mathrm{M}_{\mathrm{i}+}-\sum \mathrm{M}_{\mathrm{i}-}\right) / \mathrm{N}
$$

where $E_{x i}$ is the variable main effect, $M_{i+}$ and $M_{i-}$ are the aflatoxin production in trials where the independent variable (xi) was present in high and low concentrations, respectively, and $\mathrm{N}$ is the number of trials divided by two. A positive main effect sign indicates that a high level of this variable is nearer to maximum response, and a negative sign indicates that the low level of this variable is nearer to maximum response. An aliquot of $50 \mathrm{ml}$ of CYE broth was used as the basal culture medium, and sucrose was replaced by various forms of wheat. The inoculum size used was $2 \mathrm{ml}$ of $6 \times 10^{5}$ spores $/ \mathrm{ml}$, and the $\mathrm{pH}$ was adjusted at 7.5 with incubation for 21 days at $28^{\circ} \mathrm{C}$ under shaking at $180 \mathrm{rpm}$. To describe the nature of the response surface in the experimental region and to reveal the optimal levels of the most significant independent variables, the Box-Behnken design was applied. The most significant independent variables concluded from the Plackett-Burman experiment were yeast extract g/l (X1), carbon source $\mathrm{g} / \mathrm{l}$ (X2), and medium volume $\mathrm{ml}(\mathrm{X} 3)$. Accordingly, these variables were tested at three levels (low, basal, and high) coded $(-1,0$, and +1$)$ in 15 treatment combinations for predicting the optimal level. The following second order polynomial model was fitted to correlate relationship between independent variables and response:

$$
\begin{aligned}
Y= & \mathrm{b}_{0}+\mathrm{b}_{1} X_{1}+\mathrm{b}_{2} X_{2}+\mathrm{b}_{3} X_{3}+\mathrm{b}_{12} X_{1} X_{2}+\mathrm{b}_{13} X_{1} X_{3} \\
& +\mathrm{b}_{23} X_{2} X_{3}+\mathrm{b}_{11} X_{1}^{2}+\mathrm{b}_{22} X_{2}^{2}+\mathrm{b}_{33} X_{3}^{2}
\end{aligned}
$$

where $Y$ is the dependent variable (aflatoxin production in $\mathrm{ng} / \mathrm{mg}$ ); $X 1, X 2$, and $X 3$ are the levels of the independent variables; $b_{0}$ is the regression coefficient at the center point; $b_{1}$, $b_{2}$, and $b_{3}$ are linear coefficients; $b_{12}, b_{13}$, and $b_{23}$ are the second order interaction coefficients; and $b_{11}, b_{22}$, and $b_{33}$ are quadratic coefficients. The values of the coefficients were calculated and optimal levels were predicted using Statistica 10 software. The coefficient of determination $R^{2}$ was selected to reflect the quality of the model fitting.

\section{Effect of Wheat Husks and Wheat Husk Constituents on Aflatoxin Production by A. flavus}

The optimized condition obtained by the Box-Behnken experiment (model 4) was conducted, and the liquid cultures were autoclaved at $121^{\circ} \mathrm{C}$ for $15 \mathrm{~min}$ and then inoculated with $6 \times 10^{5}$ A. flavus spores $/ \mathrm{ml}$. Various essential oils, namely thyme, cinnamon, sweet basil, and coriander oils, were added one at a time at a concentration of 1000 ppm. In addition, individual components of wheat husks, viz. silicon dioxide, potassium oxide, calcium oxide, magnesium oxide, and ferric oxide, were added one at a time at a concentration equivalent to each individual component ratio in full wheat grains. An extract of $5 \%(\mathrm{w} / \mathrm{w})$ ground wheat husks was also added to the optimal medium, and a control was conducted under the same conditions without addition of oils or chemicals. After incubation for 21 days at $28^{\circ} \mathrm{C}$, the fungal dry weight and aflatoxin production were assayed. Chemical analysis of wheat husks and the tested essential oils were carried out at Chemistry Laboratories Administration, Egypt using FT-IR spectrometer (Nicolet iS5, Thermo Fisher) equipped with an iD7 accessory in the range of 560-3200 nm. A calibration curve was constructed for quantification of each analyte using various concentrations of the standard chemical.

\section{Statistical Analysis}

Experiments were carried out in triplicate, and the mean and standard deviation were computed. A statistical significance difference was set at a $P$-value of 0.05 . Response surface regression, which is a form of multivariate non-linear regression, was adopted.

\section{RESULTS}

\section{The Effect of Various Wheat Forms on the Production of Aflatoxins by A. flavus}

The results illustrated in Figure 1 show that full and halfcrushed wheat grains demonstrated aflatoxin levels lower than flour 82 and $72 \%$ during the entire monitoring period (525 days). Aflatoxin production by A. flavus ranged from 0.69$1.86,0.85-2.17,1.43-2.8$, and $1.47-2.85 \mathrm{ng} / \mathrm{mg}$ when grown on full wheat grains, half-crushed wheat grains, flour $82 \%$ and flour $72 \%$, respectively. At the end of the incubation period, the mycosynthesis of aflatoxins by A. flavus grown on flour 82 and $72 \%$ was higher than aflatoxins produced on full wheat grains and half-crushed wheat grains by approximately 132.2, 117.16, 145.88 , and $129.28 \%$, respectively. On the other hand, the optimal 
TABLE 1 | Predicted maximum aflatoxin production by A. flavus (ng/mg) and equations of the quadratic models based on Box-Behnken experiment.

\begin{tabular}{|c|c|c|c|c|c|}
\hline Model & Carbon source & $\begin{array}{l}\text { Carbon source } \\
\text { (g/l) }\end{array}$ & Yeast extract (g/l) & $\begin{array}{l}\text { Medium volume } \\
\qquad(\mathrm{ml})\end{array}$ & $\begin{array}{l}\text { Predicted aflatoxins production by } \\
\qquad A . \text { flavus (ng/mg) }\end{array}$ \\
\hline 1 & Full wheat grains & 12 & 2 & 25 & 1.247 \\
\hline 2 & Half crushed wheat grains & 12 & 3.5 & 75 & 1.647 \\
\hline 3 & Wheat flour $82 \%$ & 12 & 5 & 25 & 1.822 \\
\hline 4 & Wheat flour $72 \%$ & 39 & 5 & 75 & 2.567 \\
\hline Model 1 function & \multicolumn{5}{|c|}{$Y=0.63-0.36 X_{1}-0.027 X_{2}+0.07 X_{3}+0.03 X_{1}^{2}+0.0003 X_{2}^{2}-0.0007 X_{3}^{2}+0.0162 X_{1} X_{2}-0.0004 X_{1} X_{3}-0.0001 X_{2} X_{3}$} \\
\hline Model 2 function & \multicolumn{5}{|c|}{$Y=0.942+0.217 X_{1}+0.028 X_{2}+0.0075 X_{3}-0.0189 X_{1}^{2}-0.0081 X_{1} X_{2}-0.0005 X_{1} X_{3}-0.0001 X_{2} X_{3}$} \\
\hline Model 3 function & \multicolumn{5}{|c|}{$Y=0.2259-0.092 X_{1}+0.115 X_{2}+0.0575 X_{3}+0.0262 X_{1}^{2}-0.0016 X_{2}^{2}-0.0005 X_{3}^{2}-0.0191 X_{1} X_{2}-0.0002 X_{1} X_{3}+0.0002 X_{2} X_{3}$} \\
\hline Model 4 function & \multicolumn{5}{|c|}{$Y=2.159+0.1403 X_{1}+0.0223 X_{2}+0.0135 X_{3}-0.0145 X_{1}^{2}-0.0001 X_{2}^{2}-0.0002 X_{3}^{2}-0.0136 X_{1} X_{2}+0.0004 X_{1} X_{3}+0.0001 X_{2} X_{3}$} \\
\hline
\end{tabular}

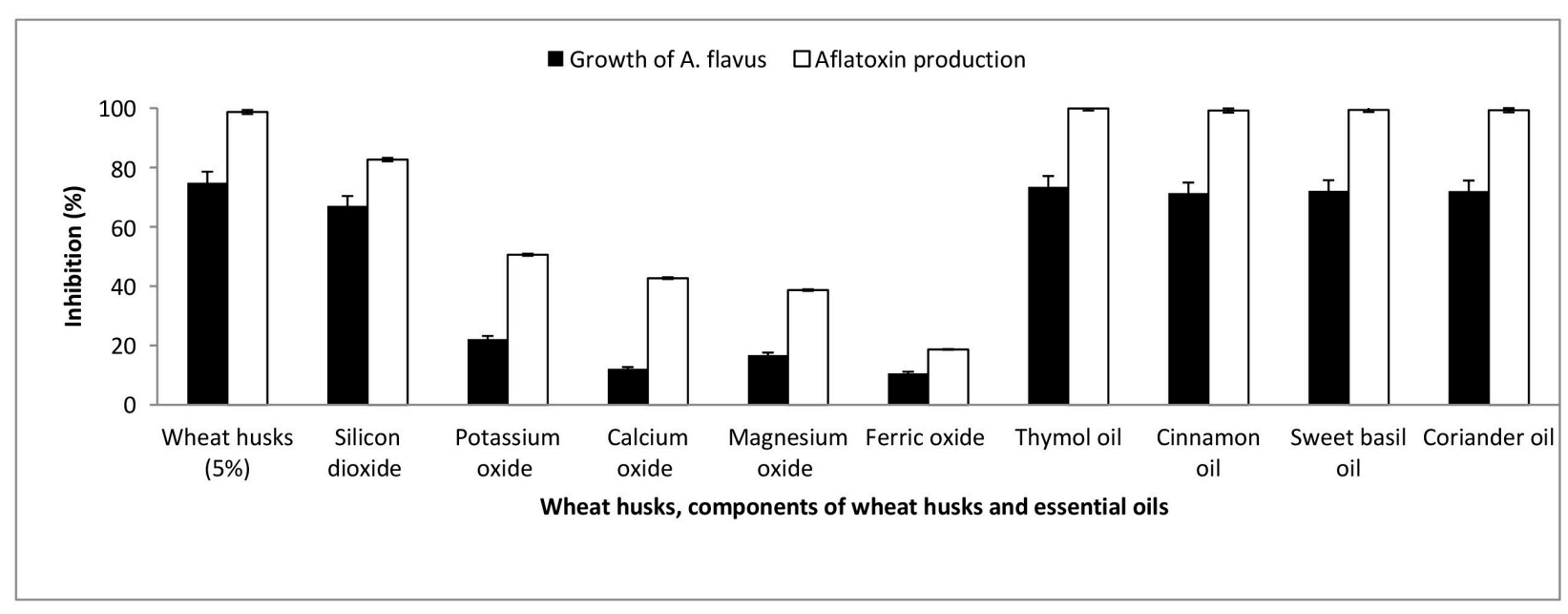

FIGURE 7 | The inhibitory effect of wheat husks, wheat husk components, and various essential oils on the growth and aflatoxin production of $A$. flavus.

incubation time was 21 days for aflatoxin production by A. flavus grown on the examined wheat forms.

\section{Elucidation of the Factors Affecting Aflatoxin Production by A. flavus}

The chosen levels of the Plackett-Burman design variables and observations are presented in Supplementary Table S1. The main effects of each variable with respect to aflatoxin formation by A. flavus grown on full wheat grains, halfcrushed wheat grains, flour $82 \%$ and flour $72 \%$ are presented in the Supplementary Material and are illustrated graphically in Figure 2.

Based on the results of the Plackett-Burman experiment, a near optimum condition for maximal aflatoxin production is as follows: yeast extract, $8 \mathrm{~g} / \mathrm{l}$; carbon source, $48 \mathrm{~g} / \mathrm{l}$; Czapek concentrate, $4 \mathrm{ml} / \mathrm{l} ; \mathrm{K}_{2} \mathrm{HPO}_{4}, 1.6 \mathrm{~g} / \mathrm{l}$; inoculum size $\left(6 \times 10^{5}\right.$ spores $/ \mathrm{ml}$ ), $1 \mathrm{ml}$; medium volume, $25 / 250 \mathrm{ml}$ Erlenmeyer flask; and medium $\mathrm{pH}, 4.5$ with an incubation period of 21 days at $28^{\circ} \mathrm{C}$ under shaking at $180 \mathrm{rpm}$.

Moreover, a significant effect $(p \leq 0.05)$ of yeast extract $(\mathrm{g} / \mathrm{l})$, carbon source $(\mathrm{g} / \mathrm{l})$, and medium volume $(\mathrm{ml}) / 250 \mathrm{ml}$ Erlenmeyer flask on aflatoxin production $(\mathrm{ng} / \mathrm{mg})$ by A. flavus was perceived. Consequently, the Box-Behnken design was adopted to determine the most favorable level of these factors relating to aflatoxin synthesis by $A$. flavus. As shown in Supplementary Table S2, the design matrix includes 15 trials, and each factor was examined at three different levels (-, 0 , and + ). The observed and predicted values of aflatoxins (ng/mg) produced by A. flavus on full wheat grains, halfcrushed wheat grains, flour $82 \%$, and flour $72 \%$ are shown in Supplementary Table S2. The values of $R^{2}$ are $0.955,0.968,0.998$, and 0.996 for the four models of aflatoxin synthesis $(\mathrm{ng} / \mathrm{mg}$ ) by A. flavus on full wheat grains, half-crushed wheat grains, flour $82 \%$, and flour $72 \%$, respectively. The values of $R^{2}$ for the predicted data of the four models are 0.966, 0.971, 0.999, and 0.998 , respectively. These values indicate a high precision of the four models and a reliable degree of fitting between predicted and observed data.

The results are also presented graphically as illustrated in Figures 3-6 to generate a contour plot of the polynomial equations. Figures 3-6 describe the effects of yeast extract (g/l), various forms of wheat as carbon sources $(\mathrm{g} / \mathrm{l})$, and medium volume $(\mathrm{ml}) / 250 \mathrm{ml}$ Erlenmeyer flask on the production of aflatoxins (ng/mg) by A. flavus. The production of aflatoxins is clearly elevated at $2 \mathrm{~g} / \mathrm{l}$ yeast extract, $10 \mathrm{~g} / \mathrm{l}$ full wheat grains, and $20 \mathrm{ml}$ medium volume (Figure 3); $4 \mathrm{~g} / \mathrm{l}$ yeast extract, $10 \mathrm{~g} / \mathrm{l}$ halfcrushed wheat grains, and $80 \mathrm{ml}$ medium volume (Figure 4); $4 \mathrm{~g} / \mathrm{l}$ yeast extract, $10 \mathrm{~g} / \mathrm{l}$ wheat flour $82 \%$, and $20 \mathrm{ml}$ medium volume 
(Figure 5); and $5 \mathrm{~g} / \mathrm{l}$ yeast extract, $30 \mathrm{~g} / \mathrm{l}$ wheat flour $72 \%$, and $80 \mathrm{ml}$ medium volume (Figure 6).

The statistical analyses of the experiment (Supplementary Table S3) were performed, and second order polynomial functions were generated with predicted maximum aflatoxin production by A. flavus (ng/mg) (Table 1).

\section{Effect of Wheat Husk Addition on Aflatoxin Production by A. flavus Compared to Various Essential Oils}

The previous finding may infer that wheat husks have a potential antimycotic activity against $A$. flavus, which results in diminished production of aflatoxin. In order to assess the effect of wheat husk addition on aflatoxin production by $A$. flavus, $5 \%(\mathrm{w} / \mathrm{w})$ ground wheat husk extract was added to the optimal medium revealed in model four. Interestingly, after incubation for 21 days at $28^{\circ} \mathrm{C}$ under shaking at $180 \mathrm{rpm}$, the addition of wheat husk extract inhibited the growth and aflatoxin formation of $A$. flavus by 74.85 and $98.72 \%$, respectively (Figure 7).

The chemical analysis of Sods 12 wheat husk cultivar revealed that $\mathrm{SiO}_{2}$ (50.3\%), $\mathrm{K}_{2} \mathrm{O}$ (10.7\%), $\mathrm{CaO}$ (7.5\%), $\mathrm{MgO}(1.3 \%)$, and $\mathrm{Fe}_{2} \mathrm{O}_{3}(1.01 \%)$ were the major components. Figure 7 shows the inhibitory effect of $\mathrm{SiO}_{2}, \mathrm{~K}_{2} \mathrm{O}, \mathrm{CaO}, \mathrm{MgO}$, and $\mathrm{Fe}_{2} \mathrm{O}_{3}$ on aflatoxin production and growth of $A$. flavus. Among the major components of wheat husks, $\mathrm{SiO}_{2}$ demonstrated the highest inhibitory effect against growth of $A$. flavus and aflatoxin production, $67.04 \%$ and $82.67 \%$, respectively. On the other hand, $\mathrm{Fe}_{2} \mathrm{O}_{3}$ exhibited the lowest antagonistic effect toward A. flavus growth and aflatoxin production, $10.06 \%$ and $18.67 \%$, respectively.

Thymol, cinnamon, sweet basil, and coriander essential oils were tested for their effect on the growth and aflatoxin production by $A$. flavus compared to wheat husks. Fifteen components representing $99.91 \%$ of thymol oil constituents were spectroscopically identified. The major components detected were p-cymene $(8.41 \%), \gamma$-terpinene $(30.90 \%)$, and thymol (47.59\%). Thymol oil strongly inhibited fungal growth and aflatoxin production by 73.46 and $99.9 \%$, respectively. Twenty components representing $99.97 \%$ of cinnamon oil constituents were spectroscopically determined. The major components were trans-Cinnamaldehyde (35.22\%), Copaene (26.47\%), $\alpha$-Muurolene (8.21\%), and $\alpha$-Cadinene (9.79\%). Cinnamon oil sharply repressed fungal growth and aflatoxin production by 71.35 and $99.2 \%$, respectively. The chemical composition of sweet basil oil revealed 25 components representing $98.6 \%$ of the oil. The major components detected were methyl eugenol (39.3\%) and methyl chavicol (38.3\%). The antifungal activity of sweet basil essential oil against A. flavus growth recorded an inhibition of $72.11 \%$ while it showed $99.4 \%$ reduction in the fungus potentiality to produce aflatoxins. Ten components representing $99.53 \%$ of coriander oil constituents were identified, and the major component was linalool (89.46\%). The coriander oil greatly inhibited fungal growth by $72 \%$, and the production of aflatoxins by $A$. flavus was intensely reduced by $99.3 \%$.

\section{DISCUSSION}

There are reports regarding the role of seed coat and its integrity on the aflatoxin production during storage (Hadavi, 2006); our results suggest that the same concept may be prevailing in wheat. On the other hand, physical, chemical, and biological control strategies of aflatoxin contamination are costly and require broad testing to confirm the absence of newly formed compounds or toxic secondary metabolites. The objective of the current study was to develop an in vitro new control strategy based on evaluating the influence of wheat husks on aflatoxin production by A. flavus in liquid culture. A. flavus grown on CYE broth containing full and half-crushed wheat grains as carbon sources demonstrated aflatoxin levels lower than flour 82 and $72 \%$. The implication of this finding is that wheat husks in the full and half-crushed wheat grains affected the biosynthesis of aflatoxins by A. flavus.

A. flavus utilizes variable levels of carbon and nitrogen sources and inorganic substances for growth and aflatoxin production in crops (Mellon et al., 2005; Rajasekaran et al., 2017). Therefore, the Plackett-Burman and Box-Behnken designs were adopted to determine the most favorable levels of environmental factors affecting the growth and aflatoxin synthesis of $A$. flavus. It was noticeable that full wheat grains supported the lowest amount of aflatoxins produced by A. flavus. Moreover, aflatoxin production followed the next descending order: full wheat grains $<$ half-crushed wheat grains $<$ wheat flour $82 \%<$ wheat flour $72 \%$. It can be supposed that these data are due to the higher presence of wheat husks in full grains and not to the readily accessible carbohydrates in milled wheat flour rather than wheat kernels. This is simply because aflatoxin production was determined in terms of specific productivity, aflatoxins (ng)/fungal dry weight (mg).

The results of the chemical analysis of wheat husks are in keeping with the findings reported by Terzioğlu and Yucel (2012): $\mathrm{SiO}_{2}$ (43.22\%), $\mathrm{K}_{2} \mathrm{O}$ (11.3\%), $\mathrm{CaO}$ (5.46\%), $\mathrm{MgO}$ (0.99\%), and $\mathrm{Fe}_{2} \mathrm{O}_{3}(0.84 \%) . \mathrm{SiO}_{2}$ demonstrated the highest inhibitory effect against $A$. flavus growth and production of aflatoxins, which may be attributed to the ability of silicon dioxide to interrupt cell functions, such as cell differentiation (Dizaj et al., 2014). Conversely, $\mathrm{Fe}_{2} \mathrm{O}_{3}$ exhibited the lowest antagonistic effect toward the growth of $A$. flavus and production of aflatoxins, which may be due to inducing the decomposition of proteins and lipopolysaccharides in the fungal cell membrane (Parveen et al., 2018). $\mathrm{Fe}_{2} \mathrm{O}_{3}$ can also cause oxidative damage to the fungal cells via penetration through disrupted membranes (Parveen et al., 2018). On the other hand, magnesium oxide, calcium oxide, and potassium oxide showed a moderate inhibitory effect on both fungal growth and aflatoxin synthesis by $A$. flavus. Calcium oxide and magnesium oxide act as potent antifungal agents due to the generation of active oxygen species and alkalinity, which damage the cell membrane leading to the leakage of intracellular contents (Yamamoto et al., 2010). As previously proposed (OrtegaAguilar et al., 2011) potassium oxide was reported to reduce sporulation, modify the colony growth patterns of fungi, and affect mycelial growth. 
An attempt was performed to compare the antifungal and antiaflatoxigenic activities of wheat husks to some essential oils that possess antimycotic properties. Thymol oil strongly inhibited fungal growth and aflatoxin production, which was attributed to the presence of phenolic compounds, thymol, and terpene hydrocarbons, $\gamma$-terpinene, with a synergistic effect (Dorman and Deans, 2000; Skočibušić et al., 2006; Rota et al., 2008; Gallucci et al., 2009). Other studies suggest another synergistic effect of the minor components of thymol oil in relation to its antifungal activity (Gill et al., 2002). Cinnamon oil sharply repressed the growth of A. flavus and aflatoxin production owing to the presence of cinnamaldehyde, which inhibits spore germination and improves lipid peroxidation and oxidative stress in A. flavus (Sun et al., 2016). Our results clearly demonstrate that sweet basil oil showed inhibitory effects against growth and aflatoxin production of A. flavus, which may be associated to the leakage of intracellular ATP and $\mathrm{K}^{+}$by the phenolic components of the oil, leading to the cell's death (Pandey et al., 2014). Coriander oil effectively inhibited aflatoxin production by A. flavus through linalool, which proved to change the functions of the fungal membrane protein leading to an electrolyte imbalance and death (Khan et al., 2010; De Oliveira Lima et al., 2017). Our study shows that, at an optimized condition, after addition of wheat husk extract, the antifungal and antiaflatoxigenic activities to A. flavus are comparable to those obtained from thymol, cinnamon, sweet basil, and coriander oils. There is a lack of published sources describing the repression mechanism of wheat husks on the biosynthesis of aflatoxins by A. flavus. Many authors reported that wheat husks efficiently protect wheat kernels from fungal infestation and their mycotoxins in vivo, but evaluation of aflatoxins is still scant (Infektion, 2004; Castoria et al., 2005; Suchowilska et al., 2010; Moudry et al., 2011; Vučković et al., 2013). Moheb et al. (2013) reported that wheat husks contain $770 \pm 157 \mathrm{mg} / \mathrm{kg}$ dry weight of the flavone tricin, which possesses effective antifungal properties (Jiang et al., 2020). Therefore, the antifungal effect of wheat husks on $A$. flavus might be also attributed to the suppression of spore germination by tricin, which

\section{REFERENCES}

Ayalew, A. (2010). Mycotoxins and surface and internal fungi of maize from Ethiopia. Afr. J. Food Agric. Nutr. Dev. 10, 4109-4123.

Bennett, J., and Klich, M. (2003). Mycotoxins. Clin. Microbiol. Rev. 16, 497-516.

Box, G. E., and Behnken, D. W. (1960). Some new three level designs for the study of quantitative variables. Technometrics 2, 455-475. doi: 10.1080/00401706. 1960.10489912

Castoria, R., Lima, G., Ferracane, R., and Ritieni, A. (2005). Occurrence of mycotoxin in farro samples from southern Italy. J. Food Protect. 68, 416-420. doi: 10.4315/0362-028x-68.2.416

Chahal, K., Singh, R., Kumar, A., and Bhardwaj, U. (2016). Antifungal potential of coriander seed essential oil and its constituents. Indian J. Ecol. 43, 292-295.

Cheli, F., Pinotti, L., Novacco, M., Ottoboni, M., Tretola, M., and Dell'Orto, V. (2017). Mycotoxins in Wheat and Mitigation Measures. London: Intechopen.

Cheli, F., Pinotti, L., Rossi, L., and Dell'Orto, V. (2013). Effect of milling procedures on mycotoxin distribution in wheat fractions: a review. LWT Food Sci. Technol. 54, 307-314. doi: 10.1016/j.lwt.2013.05.040 was previously reported on the fungal pathogen Fusarium oxysporum by Kong et al. (2010).

\section{CONCLUSION}

Wheat husks showed significant antimycotic and antiaflatoxigenic activity against $A$. flavus. The addition of husks extract to wheat containing liquid culture as a sole carbon source drastically protected the wheat from aflatoxicosis and fungal growth. To our knowledge, this is the first report on the in vitro application of a natural waste for aflatoxin control by a simple and cost-effective method. However, further studies are recommended to investigate the in vivo addition of wheat husks to various grains or nuts liable to aflatoxicosis. It is also suggested to study the impact of wheat husks on expression of genes such as aflR, aflJ, nor $A, o m t A, o m t B, p k s A, v b s$, ver-1, and hexA, which regulate aflatoxin biosynthesis in $A$. flavus.

\section{DATA AVAILABILITY STATEMENT}

All datasets generated for this study are included in the article/Supplementary Material.

\section{AUTHOR CONTRIBUTIONS}

KG, SE, and WL designed the study and supervised all of the experimental works. ME-S carried out the experiments. WL analyzed the data and wrote the manuscript. All authors contributed to the article and approved the submitted version.

\section{SUPPLEMENTARY MATERIAL}

The Supplementary Material for this article can be found online at: https://www.frontiersin.org/articles/10.3389/fmicb. 2020.01448/full\#supplementary-material

De Oliveira Lima, M., De Medeiros, A. A., Silva, K. S., Cardoso, G., De Oliveira Lima, E., and De Oliveira Pereira, F. (2017). Investigation of the antifungal potential of linalool against clinical isolates of fluconazole resistant Trichophyton rubrum. J. Mycol. Med. 27, 195-202. doi: 10.1016/j.mycmed.2017. 01.011

Debonne, E., Van Bockstaele, F., De Leyn, I., Devlieghere, F., and Eeckhout, M. (2018). Validation of in-vitro antifungal activity of thyme essential oil on Aspergillus niger and Penicillium paneum through application in par-baked wheat and sourdough bread. LWT 87, 368-378. doi: 10.1016/j.lwt.2017.09.007

Dizaj, S. M., Lotfipour, F., Barzegar-Jalali, M., Zarrintan, M. H., and Adibkia, K. (2014). Antimicrobial activity of the metals and metal oxide nanoparticles. Mater. Sci. Eng. C 44, 278-284. doi: 10.1016/j.msec.2014.08.031

Dorman, H., and Deans, S. G. (2000). Antimicrobial agents from plants: antibacterial activity of plant volatile oils. J. Appl. Microbiol. 88, 308-316. doi: 10.1046/j.1365-2672.2000.00969.x

Dorner, J. W. (2004). Biological control of aflatoxin contamination of crops. J. Toxicol. Toxin Rev. 23, 425-450. doi: 10.1081/txr-200027877

Fandohan, P., Gnonlonfin, B., Hell, K., Marasas, W., and Wingfield, M. (2005). Natural occurrence of Fusarium and subsequent fumonisin contamination in 
preharvest and stored maize in Benin, West Africa. Intern. J. Food Microbiol. 99, 173-183. doi: 10.1016/j.ijfoodmicro.2004.08.012

Food and Agriculture Organization of the United Nations [FAO] (2016). Cereal Supply and Demand Brief. In: FAO Cereal Supply and Demand Situation. Available online at: http://www.fao.org/worldfoodsituation/csdb/en/

Gallucci, M. N., Oliva, M., Casero, C., Dambolena, J., Luna, A., Zygadlo, J., et al. (2009). Antimicrobial combined action of terpenes against the food-borne microorganisms Escherichia coli, Staphylococcus aureus and Bacillus cereus. Flavour Fragran. J. 24, 348-354.

Gill, A., Delaquis, P., Russo, P., and Holley, R. (2002). Evaluation of antilisterial action of cilantro oil on vacuum packed ham. Intern. J. Food Microbiol. 73, 83-92. doi: 10.1016/s0168-1605(01)00712-7

Hadavi, E. (2006). A new approach to postharvest nut storage for quality: could seed storage principles be applied for commercial nut storage?: XXVII international horticultural congress-IHC2006: international symposium on the role of postharvest technology. Acta Hortic. 768, 335-341. doi: 10.17660/ actahortic.2008.768.44

Hell, K., Cardwell, K., Setamou, M., and Poehling, H.-M. (2000). The influence of storage practices on aflatoxin contamination in maize in four agroecological zones of Benin, West Africa. J. Stored Prod. Res. 36, 365-382. doi: 10.1016/ s0022-474x(99)00056-9

Infektion, F. (2004). Response of some cultivars of spring spelt (Triticum spelta) to Fusarium culmorum infection. Die Bodenk. 103:3.

Jiang, B., Song, J., and Jin, Y. (2020). A flavonoid monomer tricin in gramineous plants: metabolism, bio/chemosynthesis, biological properties, and toxicology. Food Chem. 320:126617. doi: 10.1016/j.foodchem.2020.126617

Khan, A., Ahmad, A., Manzoor, N., and Khan, L. A. (2010). Antifungal activities of Ocimum sanctum essential oil and its lead molecules. Nat. Product Commun. 5, 345-349.

Khorasani, S., Azizi, M. H., Barzegar, M., Hamidi-Esfahani, Z., and Kalbasi-Ashtari, A. (2017). Inhibitory effects of cinnamon, clove and celak extracts on growth of Aspergillus flavus and its aflatoxins after spraying on pistachio nuts before cold storage. J. Food Saf. 37:e12383. doi: 10.1111/jfs.12383

Kong, C. H., Xu, X. H., Zhang, M., and Zhang, S. Z. (2010). Allelochemical tricin in rice hull and its aurone isomer against rice seedling rot disease. Pest Manag. Sci. 66, 1018-1024. doi: 10.1002/ps.1976

Lotfy, W. A., Abd-El-Karim, N. M., El-Sharouny, E. E., and El-Helow, E. R. (2017). Isolation and characterization of a haloalkaliphilic protease producer bacterium from Wadi Natrun in Egypt. Afr. J. Biotechnol. 16, 1210-1220. doi: 10.5897/ ajb2017.15984

Lotfy, W. A., Atalla, R. G., Sabra, W. A., and El-Helow, E. R. (2018). Expression of extracellular polysaccharides and proteins by clinical isolates of Pseudomonas aeruginosa in response to environmental conditions. Intern. Microbiol. 21, 129-142. doi: 10.1007/s10123-018-0010-5

Lotfy, W. A., Ghanem, K. M., and El-Helow, E. R. (2007). Citric acid production by a novel Aspergillus niger isolate: I. Mutagenesis and cost reduction studies. Bioresour. Technol. 98, 3464-3469. doi: 10.1016/j.biortech.2006.11.007

Mellon, J. E., Dowd, M. K., and Cotty, P. J. (2005). Substrate utilization by Aspergillus flavus in inoculated whole corn kernels and isolated tissues. J. Agric. Food Chem. 53, 2351-2357. doi: 10.1021/jf040276g

Miller, G. L. (1959). Use of dinitrosalicylic acid reagent for determination of reducing sugar. Analyt. Chem. 31, 426-428. doi: 10.1021/ac60147a030

Moheb, A., Grondin, M., Ibrahim, R. K., Roy, R., and Sarhan, F. (2013). Winter wheat hull (husk) is a valuable source for tricin, a potential selective cytotoxic agent. Food Chem. 138, 931-937. doi: 10.1016/j.foodchem.2012.09.129

Mokbel, A. A., and Alharbi, A. A. (2015). Antifungal effects of basil and camphor essential oils against Aspergillus flavus and A. parasiticus. Austr. J. Crop Sci. 9, 532-537.

Moudry, J., Konvalina, P., Stehno, Z., and Capouchová, I. (2011). Ancient wheat species can extend biodiversity of cultivated crops. Sci. Res. Essay 6, 4273-4280. doi: $10.5897 /$ sre 11.928

Ni, X., and Streett, D. (2005). Modulation of water activity on fungicide effect on Aspergillus niger growth in sabouraud dextrose agar medium. Lett. Appl. Microbiol. 41, 428-433. doi: 10.1111/j.1472-765x.2005.01761.x

Ortega-Aguilar, B. L., Alarcón, A., and Ferrera-Cerrato, R. (2011). Effect of potassium bicarbonate on fungal growth and sclerotia of Sclerotium cepivorum and its interaction with Trichoderma. Rev. Mexican. Micol. 33, 53-61.

Pandey, A. K., Singh, P., and Tripathi, N. N. (2014). Chemistry and bioactivities of essential oils of some Ocimum species: an overview. Asian Pacif. J. Trop. Biomed. 4, 682-694. doi: 10.12980/apjtb.4.2014c77

Parveen, S., Wani, A. H., Shah, M. A., Devi, H. S., Bhat, M. Y., and Koka, J. A. (2018). Preparation, characterization and antifungal activity of iron oxide nanoparticles. Microb. Pathog. 115, 287-292. doi: 10.1016/j.micpath.2017.12.068

Plackett, R. L., and Burman, J. P. (1946). The design of optimum multifactorial experiments. Biometrika 33, 305-325. doi: 10.1093/biomet/33.4.305

Rajasekaran, K., Ford, G., Sethumadhavan, K., Carter-Wientjes, C., Bland, J., Cao, H., et al. (2017). Aspergillus flavus growth and aflatoxin production as influenced by total lipid content during growth and development of cottonseed. J. Crop Improv. 31, 91-99. doi: 10.1080/15427528.2016.1263811

Rota, M. C., Herrera, A., Martínez, R. M., Sotomayor, J. A., and Jordán, M. J. (2008). Antimicrobial activity and chemical composition of Thymus vulgaris, Thymus zygis and Thymus hyemalis essential oils. Food Control 19, 681-687. doi: 10.1016/j.foodcont.2007.07.007

Sakr, N. (2016). The role of silicon (Si) in increasing plant resistance against fungal diseases. Hell. Plant Protect. J. 9, 1-15. doi: 10.1515/hppj-2016-0001

Sisman, C. B., and Ergin, A. S. (2011). The effects of different storage buildings on wheat quality. J. Appl. Sci. 11, 2613-2619. doi: 10.3923/jas.2011.2613.2619

Siuda, R., Grabowski, A., Lenc, L., Ralcewicz, M., and Spychaj-Fabisiak, E. (2010). Influence of the degree of fusariosis on technological traits of wheat grain. Intern. J. Food Sci. Technol. 45, 2596-2604. doi: 10.1111/j.1365-2621.2010. 02438.x

Skočibušić, M., Bezić, N., and Dunkić, V. (2006). Phytochemical composition and antimicrobial activities of the essential oils from Satureja subspicata Vis. growing in Croatia. Food Chem. 96, 20-28. doi: 10.1016/j.foodchem.2005.01.051

Suchowilska, E., Kandler, W., Sulyok, M., Wiwart, M., and Krska, R. (2010). Mycotoxin profiles in the grain of Triticum monococcum, Triticum dicoccum and Triticum spelta after head infection with Fusarium culmorum. J. Sci. Food Agric. 90, 556-565.

Sun, Q., Shang, B., Wang, L., Lu, Z., and Liu, Y. (2016). Cinnamaldehyde inhibits fungal growth and aflatoxin $B 1$ biosynthesis by modulating the oxidative stress response of Aspergillus flavus. Appl. Microbiol. Biotechnol. 100, 1355-1364. doi: 10.1007/s00253-015-7159-z

Terzioğlu, P., and Yucel, S. (2012). Synthesis of magnesium silicate from wheat husk ash: effects of parameters on structural and surface properties. Bioresources 7, 5435-5447.

Van Egmond, H. P., and Jonker, M. A. (2004). Worldwide regulations on aflatoxinsThe situation in 2002. J. Toxicol. Toxin Rev. 23, 273-293. doi: 10.1081/txr200027844

Vučković, J., Bodroža-Solarov, M., Vujić, D., Bočarov-Stančić, A., and Bagi, F. (2013). The protective effect of hulls on the occurrence of Alternaria mycotoxins in spelt wheat. J. Sci. Food Agric. 93, 1996-2001. doi: 10.1002/jsfa. 6005

Yamamoto, O., Ohira, T., Alvarez, K., and Fukuda, M. (2010). Antibacterial characteristics of $\mathrm{CaCO}_{3}-\mathrm{MgO}$ composites. Mater. Sci. Eng. B 173, 208-212. doi: 10.1016/j.mseb.2009.12.007

Yin, Y.-N., Yan, L.-Y., Jiang, J.-H., and Ma, Z.-H. (2008). Biological control of aflatoxin contamination of crops. J. Zhejiang Univ. Sci. B 9, 787-792. doi: 10.1631/jzus.b0860003

Conflict of Interest: The authors declare that the research was conducted in the absence of any commercial or financial relationships that could be construed as a potential conflict of interest.

Copyright (C) 2020 Ghanem, Lotfy, El-Shaer and Elassar. This is an open-access article distributed under the terms of the Creative Commons Attribution License (CC BY). The use, distribution or reproduction in other forums is permitted, provided the original author(s) and the copyright owner(s) are credited and that the original publication in this journal is cited, in accordance with accepted academic practice. No use, distribution or reproduction is permitted which does not comply with these terms. 